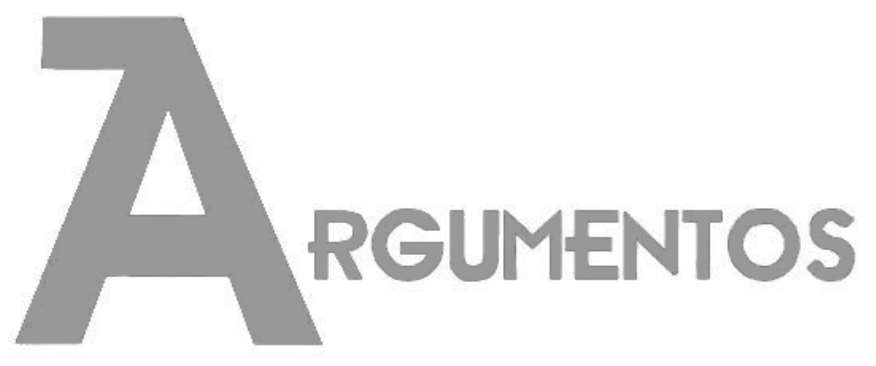

Vol. 18, n. 2, jul./dez. 2021 ISSN: 2527-2551 (online)

https://www.periodicos.unimontes.br/index.php/argumentos

\title{
Ganhando a vida? Estratégias adotadas por travestis trabalhadoras do sexo nas ruas de Montes Claros, MG
}

\author{
Giovanni Campos Fonseca ${ }^{1}$ \\ Thiago Gonçalves da Silva ${ }^{2}$ \\ Rose Elizabeth Cabral Barbosa ${ }^{3}$
}

Recebido em: 20/11/2020

Aprovado em: 12/03/2021

\begin{abstract}
Resumo: Este artigo examina estratégias adotadas por travestis trabalhadoras do sexo nas ruas de Montes Claros, Minas Gerais. O trabalho de campo envolveu entrevistas semiestruturadas com duas profissionais sobre aspectos relevantes do cotidiano de trabalho. A discussão do material empírico baseou-se na análise de conteúdo e incluiu o diálogo com estudos sobre violência contra profissionais do sexo no Brasil e no mundo. Os resultados evidenciaram que as estratégias adotadas pelas profissionais entrevistadas têm o duplo objetivo de aumentar a renda obtida com o trabalho e reduzir a exposição aos riscos de violência na atividade. Porém, em muitas circunstâncias narradas pelas trabalhadoras, essas opções são autoexcludentes. As profissionais demonstraram observar uma espécie de hierarquia de riscos e acabam tendo que optar pela exposição àqueles considerados menores nas diferentes situações enfrentadas. Em consonância com a literatura, as condutas relatadas - embora relevantes - mostraram-se insuficientes para reduzir a exposição a riscos de violência no trabalho.
\end{abstract}

Palavras-chave: Trabalho sexual; Transexual; Violência; Prevenção; Brasil.

\footnotetext{
${ }^{1}$ Doutor em Educação pela Universidade Federal de Minas Gerais, Brasil. Professor da UFMG Campus Montes Claros. Subcoordenador do Núcleo Interdisciplinar de Pesquisa em Tecnologia e Humanidades Niptech. Email: giovannifonseca@gmail.com. ORCID: http://orcid.org/0000-0003-2503-1199.

2 Graduado em Administração pela Universidade Federal de Minas Gerais, Brasil. Pesquisador associado ao Niptech - UFMG Campus Montes Claros, Brasil. Técnico de sistema de gestão Enterprise Resource Planning - ERP. E-mail: thiagogdasilva.outros@gmail.com. ORCID: https://orcid.org/0000-0001-6819$337 X$.

${ }^{3}$ Mestre em Saúde Pública, Universidade Federal de Minas Gerais, Brasil. Doutoranda em Saúde Coletiva pelo Programa de Pós-graduação em Ciências da Saúde da Universidade Estadual de Montes Claros, Brasil. E-mail: rosebarbosa.moc@gmail.com. ORCID: http://orcid.org/0000-0001-5383-0102.
} 
Artigo | Ganhando a vida? Estratégias adotadas por travestis trabalhadoras do sexo nas ruas de Montes Claros, MG (FONSECA, Giovanni Campos; SILVA, Thiago Gonçalves da; BARBOSA, Rose Elizabeth Cabral)

\section{¿Ganar la vida? Estrategias adoptadas por trabajadoras sexuales travestis en una ciudad del sureste de Brasil}

Resumen: Este artículo examina las estrategias adoptadas por las trabajadoras sexuales travestis en las calles de Montes Claros, Minas Gerais, Brasil. El trabajo de campo consistió en entrevistas semiestructuradas con dos profesionales sobre aspectos relevantes de su trabajo diario. La discusión del material empírico se basó en el análisis de contenido e incluyó el diálogo con estudios sobre violencia contra las trabajadoras sexuales en Brasil y otros países. Los resultados mostraron que las estrategias adoptadas por las profesionales entrevistados tienen el doble objetivo de incrementar los ingresos obtenidos del trabajo y reducir la exposición a los riesgos de violencia en esa actividad. Sin embargo, en muchas circunstancias narradas por ellas, estas opciones son autoexcluyentes. Las profesionales revelaron considerar una jerarquía de riesgos y, al final, deciden asumir el riesgo percibido como el menos dañino. De acuerdo con la literatura, los comportamientos reportados, aunque relevantes, son insuficientes para reducir su exposición a riesgos de violencia en el trabajo.

Palabras clave: Trabajo sexual; Transgénero; Violencia; Prevención; Brasil.

\section{Making a living? Strategies adopted by transvestite sex workers in a city of southeast Brazil}

Abstract: This article examines strategies adopted by transvestite sex workers on the streets of Montes Claros, Minas Gerais, Brazil. The field work involved semi-structured interviews with two professionals on relevant aspects of their daily work. The discussion of the empirical material was based on the content analysis and included the dialogue with studies on violence against sex workers in Brazil and other countries. The results showed that the strategies adopted by the professionals interviewed have the double objective of increasing the income obtained from work, and reducing the exposure to the risks of violence in that activity. However, in many circumstances narrated by them, these options are self-excluding. The professionals revealed to consider a hierarchy of risks, and - at the end - they decide to take the risk perceived as the less harmful. Consistent with the literature, the behaviors reported - although relevant - are insufficient to reduce their exposure to risks of violence at work.

Keywords: Sex work; Transgender; Violence; Prevention; Brazil.

\section{Introdução}

O trabalho sexual é uma atividade crescente em todo o mundo e que frequentemente expõe profissionais do sexo a situações de violência. O objetivo deste artigo é examinar estratégias adotadas por travestis trabalhadoras do sexo nas ruas de Montes Claros, Minas Gerais. Essas estratégias dividem-se em dois grupos: o primeiro é formado por tentativas de aumentar a geração de renda das trabalhadoras por meio do seu trabalho. O segundo grupo de estratégias visa a redução de riscos de violência a que as profissionais estão expostas no exercício da atividade.

Dados de pesquisas realizadas no Brasil e em países de diferentes regiões do mundo demonstram que profissionais do sexo constituem um grupo vulnerável a 
Artigo | Ganhando a vida? Estratégias adotadas por travestis trabalhadoras do sexo nas ruas de Montes Claros, MG (FONSECA, Giovanni Campos; SILVA, Thiago Gonçalves da; BARBOSA, Rose Elizabeth Cabral)

encontros violentos. Trabalhadoras de rua estão em condições ainda mais desfavoráveis se comparadas a profissionais que trabalham em locais fechados (Weitzer, 2010).

Dados de 2.523 questionários preenchidos por mulheres profissionais do sexo de dez cidades brasileiras evidenciaram que 59,5\% referiram violência verbal; 38,1\% relataram violência física praticada por parceiro íntimo, familiar ou conhecido, cliente ou agente policial. Violência sexual alguma vez na vida - seja em casa ou no trabalho foi relatada por $37,8 \%$ das mulheres profissionais do sexo (Lima et al.,2017).

Estudo realizado no interior do Piauí entrevistou 76 prostitutas que trabalhavam nas ruas. Dentre elas, $40,8 \%$ relataram já terem sido vítimas de atos violentos, tais como agressões psicológicas, físicas ou sexuais (Penha et al., 2012).

Em Miami, nos Estados Unidos, pesquisa com 294 trabalhadoras do sexo que atuavam nas ruas da cidade mostrou que $75,5 \%$ delas sofreram algum tipo de agressão nos 90 dias anteriores à entrevista. Os tipos mais comuns de atos violentos eram agressões físicas, assaltos, estupros e ameaças com armas (Kurtz et al., 2004).

Estudos sobre violência contra travestis indicam que também elas estão sujeitas a diversos riscos (Pelúcio, 2005; Carrara \& Viana, 2006; Trigo, 2008). Dentre 130 trabalhadores do sexo, incluindo mulheres, homens e transexuais da cidade de São Francisco, nos Estados Unidos, 82,0\% haviam sido vítimas de violência física em algum momento após terem começado a trabalhar nas ruas, sendo que 55,0\% desses atos foram praticados por clientes. Mulheres e transexuais eram vítimas mais frequentemente do que os homens, evidenciando que serem mulheres ou percebidas como do gênero feminino as tornavam maiores alvos de violência (Farley \& Barkan, 1998).

A discriminação estrutural da mulher na sociedade patriarcal tem o homem/masculino e heterossexual como figura central, a que se subordinariam não somente as mulheres, mas todos aqueles que transgridam o rígido modelo de sexos/gêneros e de orientação heterossexual. A violência de gênero que sofrem as mulheres atinge, portanto, também travestis e transexuais (Otero et al., 2015) e estimase que o Brasil seja atualmente o país com o maior número de mortes por violência de integrantes dessa população. 
Artigo | Ganhando a vida? Estratégias adotadas por travestis trabalhadoras do sexo nas ruas de Montes Claros, MG (FONSECA, Giovanni Campos; SILVA, Thiago Gonçalves da; BARBOSA, Rose Elizabeth Cabral)

Embora não tenhamos dados oficiais, diversas organizações nacionais e internacionais têm constituído parcerias no intuito de monitorar as situações de violência e criminalidade envolvendo a população trans. Os dados, apesar de provavelmente subestimados, revelam que o Brasil lidera o ranking dos países onde mais se matam pessoas trans (Costa-Val \& Guerra, 2019: 126).

\section{Montes Claros: polo regional de serviços e corredor rodoviário}

Montes Claros é uma cidade de médio porte localizada no Norte de Minas, com população estimada em mais de 400 mil habitantes (IBGE, 2020) e considerada polo regional por sediar indústrias, mas principalmente pelos estabelecimentos comerciais e de serviços que nela estão concentrados. Essas características fazem da cidade um destino para pessoas que nela se instalam permanentemente ou que ali permanecem por determinado período por diferentes motivos, como para estudar ou para realizar tratamento de saúde. Outros aspectos que contribuem para o grande fluxo de pessoas pela cidade são a infraestrutura de transportes que inclui aeroporto com voos regulares e estar localizada em entroncamento rodoviário que liga as regiões Sudeste, Nordeste e Centro-Oeste do Brasil. Acrescenta-se a esses fatos a frequente realização de eventos como exposições, feiras comerciais, festas tradicionais e apresentações artísticas.

Cogita-se, assim, que o trabalho sexual em Montes Claros é demandado em parte por seus habitantes mais permanentes e também por uma população flutuante diversificada. Se por um lado essa demanda potencial pressupõe maior oportunidade de geração de renda para profissionais do sexo, por outro lado é possível admitir a hipótese da intensificação de episódios de violência por parte de indivíduos que estão 'de passagem' e eventualmente inclinados a cometer abusos na expectativa de saírem ilesos pela curta permanência na cidade.

\section{Abordando o trabalho das profissionais do sexo}

O estudo apoiou-se em pesquisa exploratória e qualitativa. Os dados foram coletados por dois pesquisadores em entrevistas semiestruturadas realizadas entre agosto e outubro de 2017. Nas entrevistas buscou-se identificar detalhes sobre o cotidiano de trabalho: preparação para ir às ruas, escolha do local para trabalhar, meios de deslocamento utilizados, contato inicial com os clientes, negociação do preço e do 
Artigo | Ganhando a vida? Estratégias adotadas por travestis trabalhadoras do sexo nas ruas de Montes Claros, MG (FONSECA, Giovanni Campos; SILVA, Thiago Gonçalves da; BARBOSA, Rose Elizabeth Cabral)

conteúdo do serviço, relação com vizinhos do local de trabalho e com agentes policiais, encerramento da jornada de trabalho e o retorno para casa.

Duas travestis profissionais do sexo que trabalhavam nas ruas da cidade foram entrevistadas individualmente. Horário e local de realização das entrevistas foram determinados pelas profissionais, que leram e assinaram o Termo de Consentimento Livre e Esclarecido que integrava a documentação do estudo, devidamente aprovada pelo Comitê de Ética em Pesquisa da Universidade Federal de Minas Gerais. A gravação das entrevistas foi autorizada pelas participantes que serão identificadas neste texto pelos pseudônimos Dandara e Teresa.

A análise dos dados foi realizada por meio da técnica de análise de conteúdo, seguindo-se as etapas: 1) Pré-análise para organização dos dados; 2) Categorização dos dados; e 3) Tratamento e interpretação dos resultados (Campos, 2004). As estratégias identificadas foram, então, agrupadas em quatro tipos a partir de subtemas de destaque nas entrevistas: 1) Decidindo onde trabalhar; 2) Negociando o programa; 3) Estabelecendo a jornada de trabalho; e 4) Lidando com clientes bêbados, drogados, agressivos e rudes.

\section{Estratégias adotadas no trabalho pelas profissionais do sexo}

A adoção de estratégias no trabalho sexual é precedida pela elaboração das mesmas, que se dá por meio da aprendizagem de um conhecimento de natureza predominantemente tácita (Polanyi, 1967). Compreender esse processo de aprendizagem não constituiu foco deste estudo, mas foi objeto de outras pesquisas (França 2014; 2017).

Ao longo de sua prática na prostituição, as prostitutas aprendem a enquadrar o programa de maneira comercial. Colocam limites à interação e desenvolvem destreza corporal, interacional e emocional. Ao longo de todo o programa, elas realizam uma série de esforços, como manter a atenção a possíveis perigos, como o ataque de um cliente ou a retirada do preservativo; controlar o tempo do programa; interpretar o estilo e o desejo do cliente; adaptar sua própria atitude para realizar as fantasias demandadas; realizar suporte emocional; ser simpática e cativar o homem de maneira que ele se sinta satisfeito e volte a procurá-la (França, 2014: 328-329). 
Artigo | Ganhando a vida? Estratégias adotadas por travestis trabalhadoras do sexo nas ruas de Montes Claros, MG (FONSECA, Giovanni Campos; SILVA, Thiago Gonçalves da; BARBOSA, Rose Elizabeth Cabral)

As estratégias que aqui serão discutidas gravitam em torno da realização dos programas: por um lado para tentar fazê-los mais numerosos e rentáveis, por outro lado para tornar tais encontros menos sujeitos a atos violentos por parte dos clientes. $\mathrm{O}$ termo 'programa' é entendido aqui como encontro tarifado e negociado em termos de preço, forma de pagamento, condições e limites das interações entre a profissional e o cliente (Guimarães \& Merchán-Hamann, 2005; França, 2017). Já as 'estratégias' adotadas pelas profissionais do sexo são consideradas pela perspectiva de Mintzberg (2004). Para o autor, estratégias são em parte deliberadas ou intencionais, quando elaboradas racionalmente e com antecedência para uma finalidade pretendida pelo agente - que é a abordagem mais convencional do termo. No entanto, estratégias são também emergentes, ou seja, surgem em situações imprevistas e imprevisíveis, fundamentam-se na experiência e na intuição, o que leva o agente a criar respostas em tempo real para os eventos surgidos. Portanto, estratégias são aqui compreendidas no presente estudo como uma combinação dinâmica e em diferentes medidas entre deliberação e emergência nas ações, o que parece ser a tônica do trabalho sexual, conforme discussão a seguir.

\section{Decidindo onde trabalhar}

Ambas as entrevistadas relataram que para decidirem o local em que permaneciam aguardando clientes observavam diferentes fatores que serão discutidos adiante. No entanto, a decisão era limitada pelas regiões em que a cafetina as autorizava trabalhar. Dandara disse que para além do local que escolheu, poderia optar também por uma praça localizada no centro da cidade. Segundo ela, "é a mesma pessoa que comanda" os dois locais. Caso ela preferisse trabalhar em outros pontos, a autorização teria que ser obtida com outra pessoa.

As entrevistadas relataram efetuar pagamentos ou "pedágios" semanais para a cafetina e que por eventuais atrasos eram cobrados "juros". O não pagamento era punido pela cafetina de diferentes formas: alguém poderia receber ordem de passar de motocicleta pelo ponto de trabalho e atirar ovos ou pedras nas profissionais ou mesmo roubá-las. Por outro lado, pagamentos efetuados regularmente possibilitavam que elas 
Artigo | Ganhando a vida? Estratégias adotadas por travestis trabalhadoras do sexo nas ruas de Montes Claros, MG (FONSECA, Giovanni Campos; SILVA, Thiago Gonçalves da; BARBOSA, Rose Elizabeth Cabral)

trabalhassem sem serem importunadas, principalmente por outras profissionais do sexo que atuavam no mesmo local.

Como a gente paga as cafetinas... qualquer coisa elas resolvem... entendeu?... tipo assim... na verdade... as pessoas veem mais como uma extorsão... a gente já não acha... porque tipo assim... eu mesma sou de cidade pequena... eu vim pra cá... aí aquelas meninas que estão aqui há mais tempo... se não existisse cafetina... não iam [me] deixar [trabalhar aqui]... entendeu?... é praticamente para defender a gente... entendeu?... tipo das mais antigas... (Teresa)

Em um contexto de exposição a riscos de violência, as entrevistadas acabavam por reconhecer mais o caráter de proteção do que o de extorsão no relacionamento com a cafetina. Outros estudos (Fonseca, 1996; Brents \& Hausbeck, 2005; Willman, 2008; Katsulis et al., 2010) que abordam diferentes mecanismos de redução de violência contra trabalhadoras do sexo trazem à discussão essa relação ambígua entre profissionais do sexo e seus 'protetores'. Esses mecanismos envolvem vários recursos e agentes, sendo mais eficazes em estabelecimentos fechados, onde proprietários, gerentes, outros trabalhadores e as próprias colegas cooperam para a proteção das profissionais do sexo. No caso do trabalho na rua, cafetina ou cafetão não são necessariamente vistos como "a figura terrível do explorador profissional" (Fonseca, 1996: 30), já que em alguma medida oferecem proteção às trabalhadoras. A atuação de cafetinas como protetoras foi também relatada por travestis que participaram de estudo realizado por Pelúcio (2005).

Para decidirem em que rua trabalhar, as entrevistadas consideravam a 'valorização' do local, que estava relacionada ao preço médio do programa praticado pelas profissionais que lá atuavam. Locais com maior fluxo de pessoas tendiam, segundo elas, a atrair maior número de profissionais do sexo e a tornar mais baixos os preços dos programas, em função da maior concorrência. A compensação relativa é que locais com maior fluxo de clientes seriam menos propícios à prática de atos violentos, além de oferecerem possibilidade de realização de mais programas por jornada de trabalho (Katsulis et al., 2010).

Eu tenho de escolher o melhor local para trabalhar... entendeu?... por mim... eu trabalharia lá em cima... lá na avenida do batalhão [onde há maior fluxo 
Artigo | Ganhando a vida? Estratégias adotadas por travestis trabalhadoras do sexo nas ruas de Montes Claros, MG (FONSECA, Giovanni Campos; SILVA, Thiago Gonçalves da; BARBOSA, Rose Elizabeth Cabral)

de clientes potenciais]... mas só que lá... eu acho o programa lá muito desvalorizado... entendeu?... então eu prefiro trabalhar aqui... (Dandara)

Estudo realizado em Tijuana, no México, com 190 mulheres trabalhadoras do sexo encontrou resultados similares. Também naquele contexto, estratégias adotadas pelas profissionais estão associadas a relações cruzadas entre os fatores fluxo de clientes, competição, segurança e lucratividade (Katsulis et al., 2010).

Áreas menos centrais eram menos iluminadas e pouco transitadas, e eram essas áreas que trabalhadoras do sexo (e clientes) consideravam as mais perigosas. Porém, porque havia um menor número de trabalhadoras do sexo naquelas áreas, havia menos competição, tornando-as mais lucrativas (...) eram áreas consideradas de alto risco, mas trabalhadoras do sexo às vezes trabalhavam lá, caso tivessem menos alternativas (Katsulis et al., 2010: 350).

Havia também estratégias para decidir onde os programas seriam realizados, se em locais públicos - geralmente dentro de veículos - ou em motéis. As entrevistadas disseram que quando os programas eram realizados em motéis, os clientes escolhiam o estabelecimento de preferência. Para programas realizados em locais públicos, eram elas que determinavam o local, geralmente áreas que elas conheciam e que não consideravam perigosas. Também nesse aspecto, pesquisas revelam que realizar programas nos carros dos clientes reduz a gestão do risco por parte das profissionais (Barnard, 1993; Shannon et al., 2008; Katsulis et al., 2010). A realização de programas em veículos e o desconhecimento do local onde o encontro acontece são fatores altamente associados a episódios de violência contra as trabalhadoras do sexo (Kurtz et al., 2004).

\section{Negociando o programa: preço, forma de pagamento, condições e limites}

Dandara e Teresa disseram que logo no primeiro contato os potenciais clientes perguntavam o valor a ser pago pelo programa. O preço estabelecido variava de acordo com a duração do encontro, as práticas sexuais negociadas e o local em que seria realizado. Embora não houvesse um 'tabelamento' formal e os valores praticados variassem em diferentes regiões da cidade, os valores cobrados eram relativamente nivelados em cada região. A negociação com clientes era também parte da estratégia 
Artigo | Ganhando a vida? Estratégias adotadas por travestis trabalhadoras do sexo nas ruas de Montes Claros, MG (FONSECA, Giovanni Campos; SILVA, Thiago Gonçalves da; BARBOSA, Rose Elizabeth Cabral)

de prevenção de riscos de violência contra as trabalhadoras do sexo, que estabeleciam acordos prévios na tentativa de evitar conflitos durante e após o programa.

As entrevistas demonstraram que os clientes relacionavam-se sexualmente com elas de diversas maneiras, inclusive - e com frequência - como agentes passivos no ato sexual. Nesse particular, Dandara relatou que sua preferência era por utilizar acessórios que levava na bolsa, quando clientes pediam para que ela fosse ativa. Caso o cliente preferisse o contato físico, a entrevistada mencionou o uso de comprimidos estimulantes para atender à solicitação de clientes. Teresa, por sua vez, disse que preferia ser ativa, já que nessa condição ela se sentia mais "à vontade".

As diferenças entre os modos de operar de cada entrevistada demonstram a variabilidade presente no trabalho sexual, com uma diversidade de demandas por parte dos clientes e de ofertas por parte das profissionais. Para além da negociação comercial, as trabalhadoras tentavam estabelecer a priori condições e limites para os encontros na tentativa de conciliar geração de renda com bem-estar e segurança próprios, o que também foi documentado em outros estudos (Barnard, 1993; Sousa, 2014; França, 2014; 2017). Essa característica fazia com que a negociação com os clientes ganhasse em complexidade e exigisse diversas estratégias.

O processo de negociação entre prostitutas e clientes não parece ser fixo ou estático. Pelo contrário, ele pode ser visto como altamente dinâmico e sujeito a mudanças, a depender de diferentes contingências e pressões (Barnard, 1993: 695).

Fato recorrente na fala das entrevistadas era a insistência de clientes pelo não uso de preservativo. Ambas as profissionais foram enfáticas ao afirmar que não mantinham relações sexuais sem o uso da camisinha. No entanto, algumas verbalizações de Dandara indicaram que eventualmente ela acabava por ceder a pressões de clientes.

Eu não faço sem preservativo... eu não vou dizer pra você que eu nunca fiz sem preservativo (...) mas eu procuro fazer o possível para fazer com o preservativo... entendeu? (Dandara)

A literatura documenta várias situações semelhantes às relatadas neste estudo, como a de clientes que se recusavam a pagar pelo programa ao manifestarem 
Artigo | Ganhando a vida? Estratégias adotadas por travestis trabalhadoras do sexo nas ruas de Montes Claros, MG (FONSECA, Giovanni Campos; SILVA, Thiago Gonçalves da; BARBOSA, Rose Elizabeth Cabral)

insatisfação com o serviço porque preferiam sexo sem preservativo (Katsulis et al., 2010) ou de clientes que tentavam retirar a camisinha durante o ato sexual (Guimarães \& Merchán-Hamann, 2005). Há também na literatura relatos de casos de profissionais que concordavam com o não uso da camisinha mediante o pagamento de taxa extra (Barnard, 1993; Guimarães \& Merchán-Hamann, 2005). Outras vezes, a dispensa do uso estava ligada a um sentimento de intimidade e confiança pelo relacionamento regular que as trabalhadoras do sexo mantinham com determinados clientes (Whittaker \& Hart, 1996; Guimarães \& Merchán-Hamann, 2005; Willman, 2008).

Quando a prática sexual estava ajustada entre as partes - com condições e limites estabelecidos - e o preço combinado, era o momento de as profissionais do sexo receberem antecipadamente o pagamento. A justificativa para tal procedimento era que se o acerto financeiro fosse posterior à realização do programa, o cliente poderia se negar a pagar. Os pagamentos eram feitos em dinheiro ou com cartão bancário. Essa última forma de pagamento era disponibilizada apenas para clientes agendados pela internet e, segundo as entrevistadas, era demandada principalmente por empresários ou por representantes de empresas que visitavam a cidade por motivo de trabalho.

O uso da internet era uma estratégia de divulgação de serviços e de negociação de programas que as profissionais do sexo utilizavam paralelamente à modalidade mais convencional, que era a de permanecer em seus locais de trabalho nas ruas. Segundo as entrevistadas, a principal vantagem da utilização do meio digital era a possibilidade de praticar preços mais altos. Dandara relatou que o mesmo programa pelo qual cobrava 80 reais de um cliente com quem negociava na rua era fechado por 150 reais pela internet. As entrevistadas salientaram, no entanto, que era mais difícil convencer um cliente remotamente do que pelo contato direto.

Porque eles [os clientes] não vão estar vendo a gente, né?... tá vendo por foto... e nem sempre foto diz tudo... aí a gente... a forma de conversar por telefone... se expressar... porque essa é a primeira impressão deles sobre a gente... (Teresa)

Por propiciar número reduzido de programas, encontros agendados pela internet eram vistos como um "extra", nos termos de Dandara. Ela afirmou, no entanto, 
Artigo | Ganhando a vida? Estratégias adotadas por travestis trabalhadoras do sexo nas ruas de Montes Claros, MG (FONSECA, Giovanni Campos; SILVA, Thiago Gonçalves da; BARBOSA, Rose Elizabeth Cabral)

que quando conseguia realizar dois desses programas em um dia, ela não ia para a rua, pois considerava o ganho suficiente para "se dar uma folga".

A autonomia das profissionais do sexo que trabalham na rua para estabelecer sua jornada de trabalho é uma diferença importante em relação à atividade em estabelecimentos fechados, como bordeis, boates ou casas de massagem. Essa autonomia é um dos motivos relatados pelas trabalhadoras para permanecerem em locais públicos, mesmo considerando que nas ruas elas ficam mais expostas à violência. Nos estabelecimentos privados, geralmente exige-se o cumprimento de determinada jornada de trabalho, independentemente do número de programas realizados. O não cumprimento da jornada pode resultar em penalizações, como o pagamento de multa (Katsulis et al., 2010).

\section{Estabelecendo a jornada de trabalho}

Jornada de trabalho é o tempo compreendido entre o início e o fim das atividades laborais diárias de um trabalhador ou trabalhadora. Dandara relatou que iniciava sua jornada por volta da meia-noite. Teresa, por sua vez, começava a trabalhar logo que escurecia. Já o horário até o qual permaneciam trabalhando variava com uma série de fatores. Nos dizeres de Dandara, "a noite é uma caixinha de surpresas (...) eu posso esperar dela coisa boa e posso esperar coisa ruim também".

Um dos fatores que influenciam a duração do período diário de trabalho é o preço do programa que, como visto, depende de vários fatores, como a duração do encontro, as práticas sexuais negociadas e o local em que se realiza. Quando as trabalhadoras atuam em um ponto em que o valor do programa é mais baixo, elas tendem a prolongar a jornada na tentativa de aumentar os ganhos da noite. Ocorre que quanto mais longo o período de trabalho, maior é a exposição a riscos de violência. Portanto, a profissional do sexo está diante de um dilema quando da definição de sua jornada de trabalho.

Como em qualquer negócio, se os preços são reduzidos, as trabalhadoras terão que realizar mais programas, trabalhar muito e por mais horas para obterem a mesma quantidade de dinheiro. As trabalhadoras percebem que isso aumenta a violência porque quanto mais tempo estão 'lá fora', mais 
Artigo | Ganhando a vida? Estratégias adotadas por travestis trabalhadoras do sexo nas ruas de Montes Claros, MG (FONSECA, Giovanni Campos; SILVA, Thiago Gonçalves da; BARBOSA, Rose Elizabeth Cabral)

arriscado se torna. "Arriscamos nossas vidas cada vez que entramos nos carros: mais carros, mais riscos" (Bowen, 2006: 12).

A decisão de estender ou não a jornada de trabalho depende da percepção das trabalhadoras em relação ao fluxo de clientes e às chances de conseguirem realizar programas. Em noites de 'bom movimento', elas permanecem em atividade até próximo ao amanhecer. Já em noites cujo movimento é considerado ruim, as profissionais voltam para casa mais cedo. Outro motivo relatado pelas entrevistadas para finalizar os trabalhos de uma noite é quando se sentem cansadas.

Independentemente do motivo, a decisão de encerrar a jornada de trabalho mais cedo que o habitual gerava hesitação e resultava em desconforto para as trabalhadoras do sexo. Como a noite é "uma caixinha de surpresas", as profissionais sempre consideravam que algo poderia fazer com que o movimento de clientes aumentasse. Quando aconteciam shows na cidade, por exemplo, as trabalhadoras mantinham a expectativa de que, após o encerramento dos eventos, surgissem clientes. Elas enfrentavam, consequentemente, outro dilema: permanecer na rua em noites de pouco movimento de pessoas - o que além de não gerar resultado financeiro pode expô-las a riscos adicionais de violência - ou voltar mais cedo para casa e precisar lidar com pensamentos de como teria sido o movimento da noite, caso tivessem permanecido na rua.

Se eu voltar mais cedo [para casa] eu fico assim cismada... com isso na minha cabeça... 'ai, por que eu fui embora?... eu podia tá lá'... e aí eu fico achando que vai aparecer algum cliente... entendeu?... fico com isso na minha cabeça... entendeu?... mas me arrependo e ao mesmo tempo não me arrependo... entendeu?... é uma coisa difícil... (Dandara)

Em face dessas incertezas, as trabalhadoras do sexo geralmente procuram aproveitar ao máximo o tempo em noites consideradas de 'bom movimento'. Assim como documentado por outros estudos (Katsulis et al., 2010; França, 2014), a preferência das profissionais é por realizar programas mais curtos, chegando a utilizar a estratégia de oferecer descontos para encontros de menor duração. Outro aspecto importante para aumentar o faturamento em noites de grande fluxo de clientes é retornar para a rua o mais rapidamente possível depois de cada programa. Para isso, as entrevistadas buscavam incluir na negociação uma carona de volta ao ponto de trabalho 
Artigo | Ganhando a vida? Estratégias adotadas por travestis trabalhadoras do sexo nas ruas de Montes Claros, MG (FONSECA, Giovanni Campos; SILVA, Thiago Gonçalves da; BARBOSA, Rose Elizabeth Cabral)

ou o pagamento do transporte de retorno pelo cliente. Uma estratégia adicional para estar mais tempo disponível para os clientes era reduzir o intervalo entre programas. Para isso, elas sacrificavam até mesmo o cuidado com a aparência física, considerado por elas fundamental para atrair clientes.

Já fico parada ali na esquina mesmo [quando retorna de um programa] ... os carros já estão passando... [os clientes] já estão me vendo... ali mesmo eu já estou passando um pente no cabelo... passando um batom na boca mesmo... é coisa rápida... (Dandara)

\section{Lidando com clientes bêbados, drogados, agressivos e rudes}

Ser educada... gentil... entendeu?... por mais que o cliente seja arrogante com você... você seja educada com ele... entendeu?... você mostrar para ele que você é diferente... que você não é como ele... (Dandara)

A literatura revela que a gentileza no trato com os clientes é a principal estratégia utilizada pelas trabalhadoras do sexo para conciliar ganhos financeiros e preservação da integridade física. Por vezes, a gentileza é um mecanismo para cativar clientes e fazer com que eles voltem a procurá-las ou as indiquem para conhecidos. Outras vezes, ser gentil é uma maneira de dispensar clientes indesejados de modo relativamente cordial para não causar reações violentas. Dentre os clientes considerados indesejados pelas entrevistadas incluíam-se bêbados, drogados, agressivos e rudes - que são indivíduos "brutos" ou "mal-educados", nas palavras por elas utilizadas. Termos similares são mencionados por trabalhadoras do sexo de diferentes países para caracterizar clientes a serem evitados (Plumridge \& Abel, 2001; Kurtz et al., 2004; Izugbara, 2005; Katsulis et al., 2010; França, 2014).

As profissionais tentam perceber nos sinais mais ou menos evidentes emitidos pelos clientes potenciais, pistas que indiquem riscos de violência. A essa estratégia soma-se a tentativa por parte delas de orquestrar o encontro do início ao fim, com o intuito de evitarem a exposição a atos violentos de seus clientes (Barnard, 1993).

As trabalhadoras evitam encontros com sujeitos alcoolizados ou sob efeito de outras drogas "porque eles são muito inclinados a serem violentos, recusarem a pagar pelo sexo, insistirem em sexo sem proteção, ou a contaminá-las" (Izugbara, 2005: 153). 
Artigo | Ganhando a vida? Estratégias adotadas por travestis trabalhadoras do sexo nas ruas de Montes Claros, MG (FONSECA, Giovanni Campos; SILVA, Thiago Gonçalves da; BARBOSA, Rose Elizabeth Cabral)

A percepção dos efeitos do uso de álcool ou de drogas, porém, não é inequívoca. Algumas pessoas demonstram poucos sinais, mesmo em estado de maior acometimento e vice-versa. Há também períodos em que a substância consumida tem efeito latente para então se manifestar em momento futuro. Por um ou outro motivo, pode-se notar que essa estratégia de antecipação de riscos tem eficácia limitada. Em situações em que percebia que o possível cliente estava excessivamente alcoolizado ou sob efeito de outras drogas, Dandara preferia abrir mão de realizar o programa, não sem cuidar para que os dispensados aceitassem a negativa "numa boa" para evitar conflitos.

Clientes agressivos e rudes também eram evitados porque tais características são prenúncio de conflitos durante ou após a realização do programa. Nesse caso, os sinais externos parecem ainda mais dúbios se comparados aos indícios de embriaguez.

Quando a gente tá meio desconfiado... por exemplo... tem um mesmo que sabe nem mentir que quer aprontar... já fala 'chega aí moça... entra aí'... tipo já quer esconder o rosto... essas coisas (...) então é ser muito mal educado chegar na gente desse jeito (...) aí a gente não quer tratar mal... (...) aí eu chego a recusar... por que eu vou ficar com uma pessoa forçada? (...) aí tem uns que apelam... querem descer... brigar... tem uns que vão embora... (Teresa)

Expressão da incerteza na identificação de traços de agressividade ou rudeza foi o fato de Teresa utilizar na verbalização reproduzida acima o termo 'meio desconfiado' para caracterizar a percepção desses sinais. Novamente aqui, situações extremas de indivíduos em que a agressividade é patente poderiam ser - e possivelmente são identificadas pelas profissionais com relativa facilidade. Porém, uma conduta violenta é passível de ser escamoteada, e um sujeito aparentemente cordial em um primeiro momento pode se revelar posteriormente um agressor.

Para além das dificuldades relacionadas à identificação de sinais de clientes potencialmente geradores de problemas, a necessidade de 'ganhar a vida' pode ainda enviesar a avaliação de riscos por parte das trabalhadoras do sexo. As profissionais relataram que mesmo quando estão convencidas de que determinados clientes oferecerão riscos, é "difícil" dispensá-los porque ao mesmo tempo em que elas se preservariam de atos violentos, perderiam também oportunidades de realizar programas e receber por eles. 
Artigo | Ganhando a vida? Estratégias adotadas por travestis trabalhadoras do sexo nas ruas de Montes Claros, MG (FONSECA, Giovanni Campos; SILVA, Thiago Gonçalves da; BARBOSA, Rose Elizabeth Cabral)

Portanto, embora as estratégias adotadas pelas trabalhadoras do sexo para identificação e recusa de potenciais agressores sejam relevantes, ainda assim são insuficientes e passíveis de falhas. Isso faz com que as profissionais eventualmente recorram à proteção de terceiros - como colegas de trabalho (Barnard, 1993; Kurtz et al., 2004; Brents \& Hausbeck, 2005; Willman, 2008; Katsulis et al., 2010); cafetinas e cafetões (Shannon et al., 2008; Katsulis et al., 2010); amigos, namorados ou companheiros (Barnard, 1993; Kurtz et al., 2004; Sanders, 2004; Katsulis et al., 2010); ou a polícia (Kurtz et al., 2004; Brents \& Hausbeck, 2005; Katsulis et al., 2010).

$\mathrm{Na}$ insuficiência relativa das estratégias de proteção adotadas pelas trabalhadoras do sexo, há aquelas que lançam mão do porte de armas (Barnard, 1993; Kurtz et al., 2004; Sanders, 2004) como recurso extremo para se desvencilharem de situações de violência. Teresa verbalizou da seguinte forma o fato de sempre levar consigo uma faca.

Só para me defender... entendeu?... porém... aqui... até que... aqui nessa região que a gente trabalha é mais sossegada... a $B R$ [referindo-se à rodovia próxima] que é mais perigosa (...) porque geralmente tem roubo... quase direto... entendeu?... depois que acaba o programa... tem uns [clientes] que querem empurrar para fora do carro com o carro andando... (Teresa)

\section{Considerações finais}

As estratégias adotadas por profissionais do sexo de Montes Claros têm o duplo objetivo de aumentar a renda obtida com o trabalho e reduzir a exposição aos riscos de violência presentes na atividade. As estratégias relatadas pelas entrevistadas são em parte deliberadas, mas consistem principalmente em estratégias emergentes, adotadas de acordo com circunstâncias imprevistas e imprevisíveis no dia a dia do trabalho sexual. Fatores complexos são considerados pelas trabalhadoras do sexo na elaboração e adoção de estratégias, tornando esse conjunto de práticas igualmente complexo.

O exame das condutas que as entrevistadas neste estudo relataram colocar em prática no trabalho demonstra ser frequentemente inconciliável a tentativa de simultaneamente - aumentar a renda que obtêm e reduzir os riscos de serem vítimas de violência. Em muitas circunstâncias por elas narradas, essas opções são na verdade 
Artigo | Ganhando a vida? Estratégias adotadas por travestis trabalhadoras do sexo nas ruas de Montes Claros, MG (FONSECA, Giovanni Campos; SILVA, Thiago Gonçalves da; BARBOSA, Rose Elizabeth Cabral)

autoexcludentes. Não se trata, portanto, de conciliar tais objetivos, mas de decidir por um ou por outro. Como ganhar a vida é inescapável, por vezes elas observam uma espécie de hierarquia de riscos e acabam tendo que optar pela exposição àqueles considerados relativamente menores.

Há um limite relevante a ser considerado na interpretação dos resultados desta investigação. Por se tratar de um estudo de caso, não se podem generalizar as análises aqui realizadas. O diálogo com outros estudos sobre o tema realizados no Brasil e no exterior visou mitigar essa limitação, mas novas pesquisas com maior população de estudo e com diferentes abordagens metodológicas trarão contribuição importante para a melhor compreensão do fenômeno em tela.

Ressalta-se que o conjunto de estratégias adotadas pelas entrevistadas para reduzir a exposição aos riscos de violência, embora relevantes, são insuficientes e passíveis de falhas. Nos relatos das entrevistadas, o trabalho sexual caracteriza-se como um misto de cooperação e competição em que sobressai a rivalidade. Essa característica da atividade repercute na adoção de estratégias individuais de efeito limitado, ficando as trabalhadoras entregues à própria sorte. O que se nota é uma luta diária por parte dessas profissionais para ganhar a vida sem perder a dignidade, a saúde e - no limite sem perder a própria vida.

\section{Referências}

BARNARD, Marina. Violence and vulnerability: conditions of work for streetworking prostitutes. Sociology of Health \& Illness. v. 15, n. 5, p. 683-705, 1993.

BOWEN, Raven. From the curb: sex workers' perspectives on violence and domestic trafficking. Vancouver, BC: British Columbia Coalition of Experiential Women, 2006. Disponível em: $\quad$ http://www.pace-society.org/library/final-report-violence-and-domestic-traffickingbccew.pdf>. Acesso em 24 nov. 2020.

BRENTS, Barbara; HAUSBECK, Kathryn. Violence and legalized brothel prostitution in Nevada. Journal of Interpersonal Violence. v. 20, n. 3, p. 270-295, mar, 2005.

CAMPOS, Claudinei José Gomes. Método de análise de conteúdo: ferramenta para a análise de dados qualitativos no campo da saúde. Revista Brasileira de Enfermagem. v. 57, n. 5, p. 611-614, set-out, 2004.

CARRARA, Sérgio; VIANNA, Adriana. 'Tá lá o corpo estendido no chão...': a violência letal contra travestis no município do Rio de Janeiro. PHYSIS: Revista de Saúde Coletiva. v. 16, n. 2, p. 233-249, 2006.

COSTA-VAL, Alexandre; GUERRA, Andréa. Corpos trans: um ensaio sobre normas, singularidades e acontecimento político. Saúde \& Sociedade. v. 28, n. 1, p. 121-134, 2019. 
Artigo | Ganhando a vida? Estratégias adotadas por travestis trabalhadoras do sexo nas ruas de Montes Claros, MG (FONSECA, Giovanni Campos; SILVA, Thiago Gonçalves da; BARBOSA, Rose Elizabeth Cabral)

FARLEY, Melissa; BARKAN, Howard. Prostitution, violence, and posttraumatic stress disorder. Women and Health. v. 27, n. 3, p. 37-49, 1998.

FONSECA, Cláudia. A dupla carreira da mulher prostituta. Revista Estudos Feministas. v. 4, n. 1, p. 7-33, 1996.

FRANÇA, Marina Veiga. Quando a intimidade sobe e desce as escadas da zona boêmia de Belo Horizonte. Cadernos Pagu. v.43, p. 321-346, jul-dez, 2014.

A vida pessoal de trabalhadoras do sexo: dilemas de mulheres de classes populares. Sexualidad, Salud y Sociedad. v. 25, p. 134-155, abr, 2017.

GUIMARÃES, Kátia; MERCHÁN-HAMANN, Edgar. Comercializando fantasias: a representação social da prostituição, dilemas da profissão e a construção da cidadania. Revista Estudos Feministas. v. 13, n. 3, p. 525-544, set-dez, 2005.

IBGE. Instituto Brasileiro de Geografia e Estatística. Disponível em: $<$ https://cidades.ibge.gov.br/brasil/mg/montes-claros/panorama>. Acesso em: 24 nov. 2020.

IZUGBARA, Chimaraoke. 'Ashawo suppose shine her eyes': female sex workers and sex work risks in Nigeria. Health, Risk and Society. v. 7, n. 2, p. 141-159, jun, 2005.

KATSULIS, Yasmina et al. Female sex workers and the social context of workplace violence in Tijuana, Mexico. Medical Anthropology Quarterly. v. 24, n. 3, p. 344-362, 2010.

KURTZ, Steven et al. Sex work and 'date' violence. Violence against Women. v. 10, n. 4, p. 357-385, 2004.

LIMA, Francisca Sueli da Silva et al. Fatores associados à violência contra mulheres profissionais do sexo de dez cidades brasileiras. Cadernos de Saúde Pública [online]. v. 33, n.2, e00157815, 2017. Disponível em: <http://www.scielo.br/pdf/csp/v33n2/1678-4464-csp-33-02e00157815.pdf>. Acesso em: 24 nov. 2020.

MINTZBERG, Henry. Ascensão e queda do planejamento estratégico. Porto Alegre: Bookman, 2004.

OTERO, Luis Manuel Rodríguez et al. Violencia en parejas transexuales, transgénero e intersexuales: una revisión bibliográfica. Saúde \& Sociedade. v. 24, n.3, p. 914-935, 2015.

PELÚCIO, Larissa. Na noite nem todos os gatos são pardos: notas sobre a prostituição travesti. Cadernos Pagu. v. 25, p. 217-248, 2005.

PENHA, Jardeliny Corrêa da et al. Caracterização da violência física sofrida por prostitutas do interior piauiense. Revista Brasileira de Enfermagem. v. 65, n. 6, p. 984-990, novdez, 2012.

PLUMRIDGE, Libby; ABEL, Gillian. A 'segmented' sex industry in New Zealand: sexual and personal safety of female sex workers. Australian and New Zealand Journal of Public Health. v. 25, n. 1, p. 78-83, 2001.

POLANYI, Michael. The tacit dimension. New York: Anchor, 1967.

SANDERS, Teela. A continuum of risk? The management of health, physical and emotional risks by female sex workers. Sociology of Health \& IIIness, v. 26, n. 5, p. 557-574, 2004.

SHANNON, Kate et al. Social and structural violence and power relations in mitigating HIV risk of drug-using women in survival sex work. Social Science and Medicine. v. 66, n. 4, p. 911-921, fev, 2008.

SOUSA, Fabiana. Entre o medo e a ousadia: educando-se na prática da prostituição. Revista Ártemis. v. 18, n.1, p. 61-66, jul-dez, 2014. 
Artigo | Ganhando a vida? Estratégias adotadas por travestis trabalhadoras do sexo nas ruas de Montes Claros, MG (FONSECA, Giovanni Campos; SILVA, Thiago Gonçalves da; BARBOSA, Rose Elizabeth Cabral)

TRIGO, Luiz Gonzaga Godoi. Travesti: prostituição, sexo, gênero e cultura no Brasil. Cadernos de Saúde Pública. v. 24, n. 9, p. 2195-2196, set, 2008.

WEITZER, Ronald. Sex work: paradigms and policies. In: Sex for sale: prostitution, pornography, and the sex industry. 2 ed. New York: Routledge, p. 1-43, 2010.

WHITTAKER, Dawn; HART, Graham. Research note: managing risks: the social organization of indoor sex work. Sociology of Health and Illness. v. 18, n.3, p. 399-414, 1996.

WILLMAN, Alys. Safety first, then condoms: commercial sex, risky behavior, and the spread of HIV/AIDS in Managua, Nicaragua. Feminist Economics. v. 14, n. 4, p. 37-65, 2008. 